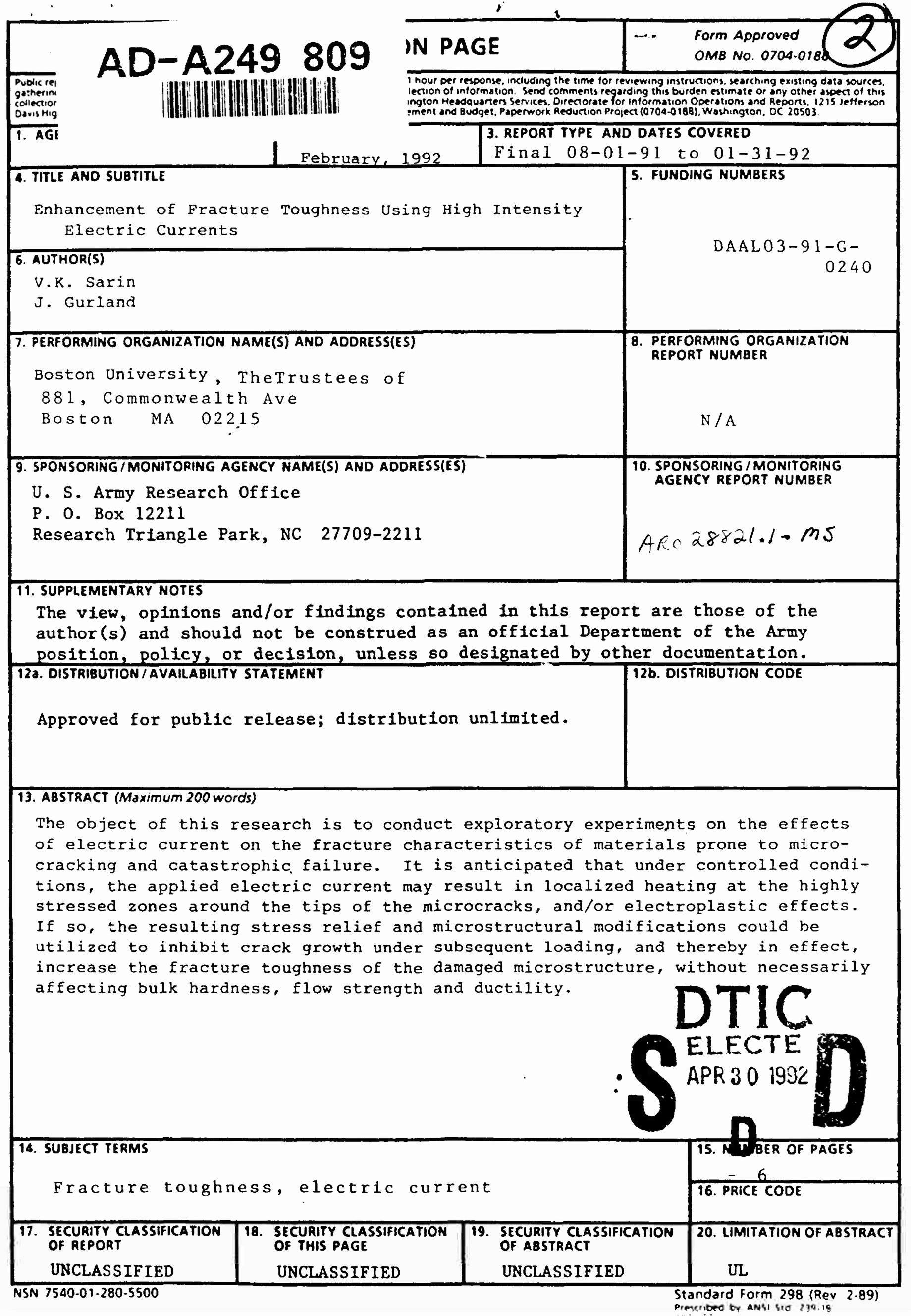


ENHANCEMENT OF FRACTURE TOUGHNESS USING

HIGH INTENSITY ELECTRIC CURRENTS

Authors

Professor V. K. Sarin

Professor J. Gurland

Date: Apri1 8, 192

U.S. ARMY RESEARCH OFFICE

Contract Number:. E02 DAAL03-91-G-0240

Department of Manufacturing Engineering BOSTON UNIVERSITY

APPROVED FOR PUBLIC RELEASE

DISTRIBUTION UNLIMITED

\begin{tabular}{|c|c|c|}
\hline \multicolumn{3}{|c|}{ Accesion for } \\
\hline $\begin{array}{l}\text { NTIS } \\
\text { DTIC } \\
\text { Uiian } \\
\text { Jusiti }\end{array}$ & $\begin{array}{l}\text { CRA\&I } \\
\text { TAB } \\
\text { Odiiced } \\
\text { Cation }\end{array}$ & $\begin{array}{l}d \\
\square \\
i j\end{array}$ \\
\hline $\begin{array}{l}\text { By } \ldots \\
\text { Dist it }\end{array}$ & :tion! & \\
\hline & vallablity aci & 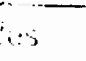 \\
\hline-1 & $\begin{array}{c}\text { Avaid a u } \\
\text { Spucul } \\
\vdots \\
1\end{array}$ & \\
\hline
\end{tabular}

$92 \quad 4 \quad 28 \quad 275$ 


\section{Enhancement of Fracture Toughness Using High Intensity Electric Currents}

\section{Background}

In recent years there has been a tremendous interest in the fracture behavior of structural materials. One reason for this is the need and use of brittle materials with relatively higher elevated temperature strengths in the aircraft, automotive, and other energy related industries. Exhaustive research is ongoing to try to enhance the fracture toughness of these materials. Most of the recent developments have been geared towards microstructural tailoring via the composite approach. Although considerable success has been achieved, the introduction of such complex processes has lead to product reliability problems, preventing their introduction in commercial applications for which they have been specifically designed. Supplementary techniques of enhancing fracture toughness of materials with defects or damage on the microscale would not only be highly desirable, but could considerably expedite the commercial utilization of some of these materials.

A new concept that hypothesized the application of high-intensity electric currents (HIEC) to modify the toughness characteristics of brittle materials has been forwarded. It was suggested that under controlled conditions, the applied electric current may result in localized heating, and/or electroplastic effects at the highly stressed zones around the tips of the microcracks. If so, the resulting stress relief and microstructural modifications could be utilized to inhibit crack growth under subsequent loading, and thereby in effect, increase the fracture toughness of the damaged microstructure, without necessarily affecting bulk hardness, flow strength and ductility. Based on this concept a feasibility study was conducted to try to establish the validity of this hypothesis.

\section{Material}

Several compositions of WC-\%Co cemented carbides, were initially investigated (Table 1). These represent a hard and brittle class of materials in which a combination of both brittle (WC) and ductile (the binder: a solid solution of $\mathrm{Co}[\mathrm{W}, \mathrm{C}])$ modes of fracture must occur for cracks to propagate. Since the fracture processes in this system are fairly well understood [1,2], it was therefore 
felt that interpretation of any observed effects of current would be easier. It is generally agreed that the crack first extends along or through the carbide phase, resulting in a connected volume of isolated binder ligaments acting as "bridges". As the crack opens, the ligaments are stretched until they rupture. Therefore, catastrophic fracture in these materials is preceded by a stage of stable crack propagation involving discontinuous microcracking in front of the crack tip. Due to the lowering of the $\mathrm{M}_{\mathrm{S}}$ temperature by the presence of $\mathrm{W}$ and $\mathrm{C}$ in the $\mathrm{Co}$, which effectively retards the martensitic (fcc to hcp) transformation, the binder is present mainly in the high temperature fcc modification. Subsequently, being unstable, stress results in partial transformation of the binder from the fcc to the hcp modification [3]. This transformation, effectively makes the binder phase relatively brittle, resulting in enhanced crack propagation. This effect is unique to the system in that it allows for connection of microcracks through the ductile binder ligaments, thus resulting in catastrophic failure. It is projected that such transformations would be concentrated around crack tips. The effect of HIEC on this transformation is therefore of great interest. Additionally, it is known that the fracture toughness of cemented carbides is rather insensitive to moderate temperature changes. Therefore, this system was considered ideal for the initial exploratory experiments.

\section{Experimental Procedure}

The as-received-samples from each of the four categories (Table 1) were cut into small cubes and randomly divided into four groups. Samples from two of these groups were uniaxially compressed at approximately 2758. MPa (approximately half the known compressive strength). All samples were then mounted and metallographically polished using previously developed techniques $[4,5]$ to minimize residual surface stress due to polishing.

Table 1 Nominal compositions of Commercial Materials Investigated

\begin{tabular}{|c|c|c|c|c|}
\hline SAMPLE & \multicolumn{2}{|c|}{ NOMI NAL COMPOSI TION (wt.\%) } & WC GRAIN SIZE \\
\hline & WC & Co & Cubic Carbides & $\mu$ \\
\hline & & & (TiC,TaC,NbC,etc.) & \\
\hline 1 & & & & 0.5 \\
\hline 2 & 93.50 & 6 & 0.5 & Fine $(\sim 1)$ \\
\hline 3 & 93.50 & 6 & 0.2 & Coarse $(4-5)$ \\
\hline 4 & 93.81 & 6 & 20.5 & Fine $(1-2)$ \\
\hline
\end{tabular}


Appropriate samples were then subjected to the HIEC treatment. A schematic of the apparatus developed for these tests is shown in Figure 1. The DC power supply used had a maximum rating of a 100 amperes, and therefore only the lower end of the current density spectrum (Table 2) could be investigated at this stage. Additionally, due to time limitations, all samples were subjected to a single 1 sec. HIEC pulse. It is evident that considerable more testing in terms of process parameters such as, larger current densities, several pulse cycles, AC versus DC currents, to name of few, need to be investigated before the full potential of this technique can be evaluated.

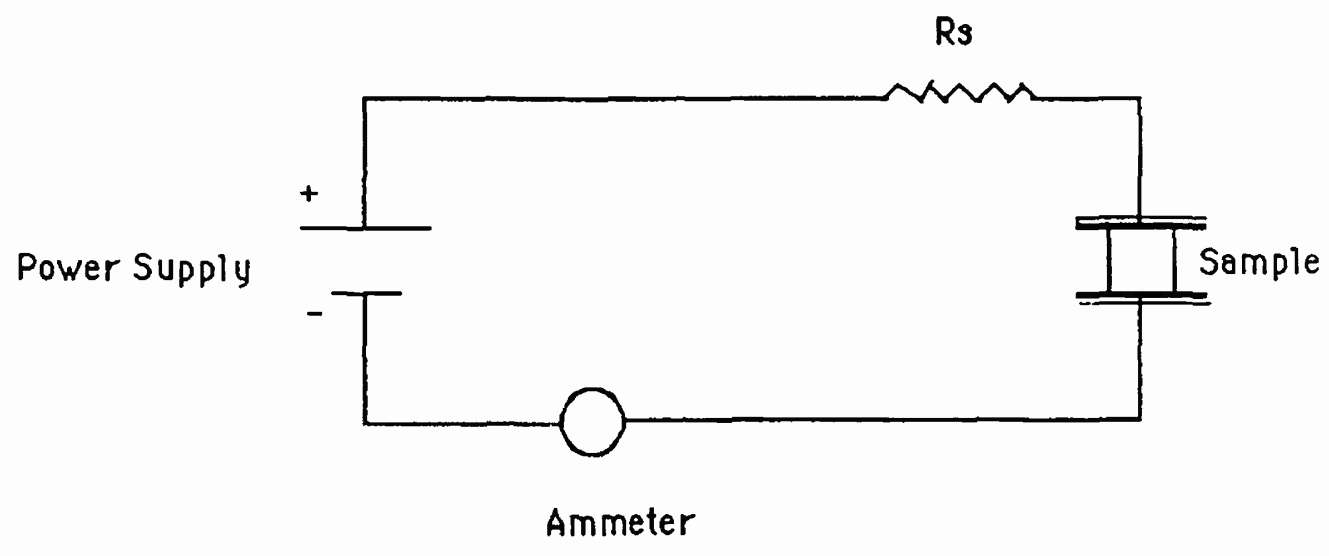

Figure 1. Schematic of the HIEC Apparatus

Surface Fracture Toughness (IFT) and Vickers hardness (H) were determined on polished specimens after the various trcatments. A minimum of twelve and up to twenty indentations (which was the case for all data points generated) using $1 \mathrm{Kg}$ load were used to establish each hardness value. Standard procedures were used to calculate the Vickers hardness number. IFT was determined by generating cracks at a $45 \mathrm{Kg}$ load with a Vickers diamond. The lengths of the cracks emanating from the corners of the indentations wire measured, and fracture toughness (IFT) was determined using the folls wing equation [6].

$$
\mathrm{IFT}=0.113(\mathrm{H})(\mathrm{D})^{1 / 2} /\left(1+\mathrm{C}_{\mathrm{L}} / 2 \mathrm{D}\right)^{3 / 2}
$$

where $\mathrm{H}=$ Vickers hardness, $\mathrm{D}=$ average Vickers diagonal, $\mathrm{C}_{\mathrm{L}}=$ :ctal crack length $\left(C_{1}+C_{2}+C_{-3}+C_{4}\right.$ - length of crack emanating from each corner of indentation). 


\section{Results and Discussion}

Table 2 summarizes the results obtained in this limited feasibility study. Inconsistencies and gaps in both process prameters and material microstructures are due to the fact that several of these remain under invetigation. It should be noted that although statistically valid, these results are very preliminary in nature and need considerably more testing and analysis before they can be confirmed. Some interesting trends are highlighted below;

Table 2 Compiled Hardness and Fracture Toughness Data

\begin{tabular}{|c|l|c|c|c|c|c|}
\hline SAMPLE & TREATMENT & CRACK LEN. & DIAGONAL & HARDNESS & IFT & CUR. DEN. \\
\hline & & $\mu$ & $\mu$ & $\mathrm{Kg} /(\mathrm{mm}) \mathbf{2}$ & MPa. m1/2 & A/(mm)2 \\
\hline $1 \mathrm{a}$ & As Received & 413.0 & 264.00 & 1885 & 14.54 & \\
\hline $1 \mathrm{~b}$ & As Rec. \& HIEC & 490.0 & 229.40 & 1904 & 14.08 & 2.35 \\
\hline $1 \mathrm{c}$ & Compressed & 462.0 & 259.20 & 1839 & 12.86 & \\
\hline $1 \mathrm{~d}$ & Comp. \& HIEC & 453.0 & 259.20 & 1878 & 13.31 & 2.35 \\
\hline $2 \mathrm{a}$ & As Received & 231.9 & 288.54 & 1218 & 14.09 & \\
\hline $2 \mathrm{~b}$ & As Rec. \& HIEC & 171.4 & 290.47 & 1230 & 16.08 & 14.45 \\
\hline $2 \mathrm{c}$ & Compressed & 338.4 & 289.25 & 1233 & 11.87 & \\
\hline $2 \mathrm{~d}$ & Comp. \& HIEC & 216.5 & 288.86 & 1237 & 14.74 & 14.45 \\
\hline 3a & As Received & 474.2 & 230.35 & 1660 & 9.85 & \\
\hline $3 \mathrm{~b}$ & Compressed & 528.3 & 230.72 & 1657 & 8.90 & \\
\hline $3 \mathrm{c}$ & Comp. \& HIEC & 464.3 & 230.08 & 1670 & 10.05 & 2.5 \\
\hline $4 \mathrm{a}$ & As Received & 353.9 & 236.75 & 1592 & 11.98 & \\
\hline $4 \mathrm{~b}$ & Compressed & 437.3 & 235.74 & 1613 & 10.46 & \\
\hline $4 \mathrm{c}$ & Comp. \& HIEC & 409.9 & 236.06 & 1608 & 10.94 & 3.9 \\
\hline
\end{tabular}

1) Hardness values are not significantly effected by either compression or HIEC treatment.

2) In all cases a decrease between $10-15 \%$ in the as received IFT values after compression was obtained.

3) An increase between $3-24 \%$ in the IFT values after the HIEC treatment of the compressed specimens

4) In category 1 , the HIEC treatment had no effect on the as received material, however specimens in group 2 showed significant improvement $(14 \%)$ in their IFT values

5) Limited test results indicate that the presence of a large amount of cubic carbides adversely effect the influence of the HIEC treatment.

The compression result are not surprising since defects introduced by deformation should be microscopic in nature (micro-cracks). Hence, as a 
consequence, no influence on a "bulk" property such as hardness is observed while a substantial decrease in fracture toughness (IFT values) is obtained, since it is greatly influenced by local defects. Impressive increases in the IFT values of the compressed samples, especially for the group 2 case, after the HIEC treatment clearly demonstrates the feasibility of this concept. Although preliminary in nature these results are extremely exciting and encouraging. Additionally, it should be noted that due to the feasibility nature of this investigation, several effects of the HIEC treatment have not been fully analyzed.

Due to the limitation of the power supply, high current densities could not be generated. However, it is interesting to note that samples (group 2) that were subjected to the highest current densities $\left(14.45 \mathrm{~A} / \mathrm{mm}^{2}\right)$, show the most significant improvement in IFT after the HIEC treatment. In these samples an increase of approximately $14 \%$ was obtained when the as-received-samples were HIEC treated, whereas an increase of $24 \%$ in the IFT values was observed when the compressed samples were HIEC treated. These increases are phenomenal and extremely exciting. However, it should be pointed out that these tremendous improvements could also be influenced by microstructural factors such as WC grain size and binder mean free path. In the case of fine grained materials (group 1) and low current densities $\left(2.35 \mathrm{~A} / \mathrm{mm}^{2}\right)$ only modest increases were observed. Needless to say, considerable more testing and in depth analysis are necessary before the influence of grain size and density can be isolated and fully understood. Furthermore, it seems that the HIEC treatment has an effect on the fcc to hcp transformation as can be clearly seen between the changes in IFT values observed in samples $2 \mathrm{a}$ and $2 \mathrm{~b}$. Clearly more work and testing is again necessary to further elucidate this effect.

Preliminary tests indicate that the presence of cubic carbides (group 4) seems to nullify the effect of HIEC treatment. It is projected that this may be due to the influence these additions have on the binder composition. However, due to the limited nature of the tests, a postive conclusion cannot be made.

\section{Conclusions}

Feasibility studies have clearly demonstrated that the application of high intensity electric current (HIEC) on damaged microstructures (compressed samples) consistently enhances their fracture toughness (IFT). In certain cases, enhancement in IFT was also observed on the as-received-samples after HIEC treatment. These results unquestionably demonstrate the HIEC treatment can definitely be used to improve the toughness of damaged WC-Co cemented carbide materials. However, considerable more testing and analysis need to be performed on a variety of brittle material systems before the full scope and potential of this process can be fully realized. 


\section{References}

1. H. F. Fischmeister, S. Schauder, and L.S.Sigl, Science of Hard Materials 3, V.K. Sarin ed.,Elsevier, Essex, England, (1988), p. 305.

2. R.Godse, and J.Gurland, Science of Hard Materials 3, V.K.Sarin ed.,Elsevier, Essex, England, (1988), p. 331.

3. V.K. Sarin and T. Johannesson, Metal Sci. 10 (1975), p 472.

4. M.T. Laugier, Journal of Material Science Letters, 1987, 897-900.

5. V.K. Sarin, Internal GTE Report.

6. A.G. Eavans, and E.A. Charles, Journal of Ameriacan Ceramic Society, 59(7-8), 1976, p371. 